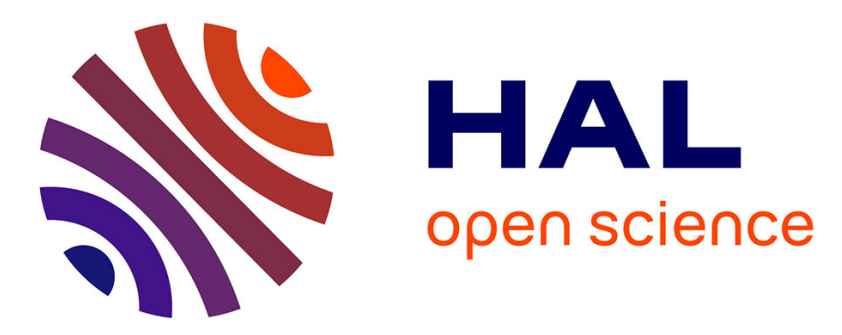

\title{
Measurement of sensitivity to dynamic strain aging in C-Mn steels by internal friction experiments.
}

Danièle Wagner, Nicolas Roubier, Claude Prioul

\section{To cite this version:}

Danièle Wagner, Nicolas Roubier, Claude Prioul. Measurement of sensitivity to dynamic strain aging in C-Mn steels by internal friction experiments.. Materials Science and Technology, 2006, 22 (3), pp.301-307. 10.1179/174328406X86155 . hal-00020227

\section{HAL Id: hal-00020227 \\ https://hal.science/hal-00020227}

Submitted on 22 Jan 2018

HAL is a multi-disciplinary open access archive for the deposit and dissemination of scientific research documents, whether they are published or not. The documents may come from teaching and research institutions in France or abroad, or from public or private research centers.
L'archive ouverte pluridisciplinaire HAL, est destinée au dépôt et à la diffusion de documents scientifiques de niveau recherche, publiés ou non, émanant des établissements d'enseignement et de recherche français ou étrangers, des laboratoires publics ou privés. 


\title{
Measurement of sensitivity to dynamic strain aging in $\mathrm{C}-\mathrm{Mn}$ steels by internal friction experiments
}

\author{
D. Wagner*1, N. Roubier ${ }^{2}$ and C. Prioul ${ }^{2}$
}

\begin{abstract}
The dynamic strain aging (DSA) phenomenon is present in C-Mn steels and associated welds commonly used in many industrial applications. This phenomenon, which appears in metals containing solute atoms interacting with dislocations, induces an increase in flow stress and ultimate tensile strength (UTS) as well as a decrease in ductility. The DSA phenomenon was studied by tensile, strain rate sensitivity and internal friction tests between $20^{\circ} \mathrm{C}$ and $350^{\circ} \mathrm{C}$ in two C-Mn steels with very different sensitivities to DSA (a fully killed A42 steel and a semikilled A48 steel). The internal friction technique, which allows one to evaluate the balance between carbon and nitrogen atoms free in the lattice and carbon and nitrogen atoms interacting with mobile dislocations, appears to give results well correlated with those obtained by tensile (and strain rate sensitivity) tests. The ductility loss or the UTS increase is shown to be proportional to Snoek peak height. It is concluded that, even in industrial materials, a single internal friction test can give a good evaluation of DSA sensitivity.
\end{abstract}

Keywords: Dynamic strain aging, C-Mn steels, Internal friction tests, Tensile tests, Strain rate sensitivity tests

\section{Introduction}

Carbon-manganese steels, in the form of pipes, plates and forgings, and associated welds are commonly used for pressurised water reactor secondary systems (feedwater line and steam line). Nevertheless, if they are insufficiently killed, these steels are well known to be sensitive to dynamic strain aging (DSA). This phenomenon, ${ }^{1-8}$ induces an increase in flow stress, ultimate tensile strength and work hardening coefficient, as well as a decrease in ductility (elongation, reduction of area) and fracture toughness. DSA is due to the presence of solute atoms, which are able to diffuse over short distances and pin mobile dislocations. Therefore, the temperature range (mobility of solute atoms) and the strain rate (dislocation velocity) required to observe these interactions between mobile dislocations and diffusing atoms, are strongly dependent on the composition and thermomechanical treatment of the materials. The physical models ${ }^{3,6}$ usually proposed to interpret the experimental results are based on a discontinuous motion of the dislocations, which are temporarily arrested on localised obstacles. During this waiting time, the solute atoms diffuse to dislocations and increase the strength of these obstacles. Within the DSA range, where the strain rate sensitivity coefficient

${ }^{1}$ LEEE, EA387, Université de Paris $X$ Nanterre, 1, chemin Desvallières, 92410 Ville d'Avray, France

${ }^{2}$ L MSS/MAT, UMR CNRS n 8579 , Ecole Centrale de Paris, 92295 Chatenay Malabry - France

*Corresponding author, email daniele.wagner@u-paris10.fr
$S=\frac{\partial \sigma}{\partial \ln \dot{\varepsilon}}$ becomes negative, well known localised deformation bands ${ }^{9-12}$ (called Portevin-Le Chatelier bands) occur during the tensile test. On the stress-strain curve, these features produce serrated yielding.

In C-Mn steels, it is well established that the diffusing species are interstitial carbon and nitrogen atoms. Moreover, according to its greater solubility limit ${ }^{13,14}$ nitrogen seems to exert a more pronounced influence on strain aging than carbon does. Depending on the diffusion coefficients, the chemical composition of the steels and the strain rate, the temperature range over which DSA occurs can vary from 200 to $350^{\circ} \mathrm{C} .^{7,8}$ This coincidence with the operating temperature range of the secondary lines of pressurised water reactors (PWR), leads to the necessity for a good estimation of the sensitivity to DSA of the in service steels.

To measure the sensitivity to DSA, tensile tests and more accurate strain rate sensitivity tests are needed in the temperature domain where DSA occurs. This means that the sensitivity to DSA can only be characterised through a large number of tests. The internal friction technique allows an evaluation of the balance between carbon and nitrogen atoms free in the lattice and carbon and nitrogen atoms interacting with mobile dislocations. So, it seems interesting to correlate this technique with tensile and strain rate sensitivity tests in order to characterise the sensitivity of a material to DSA (from an engineering point of view) with a unique test.

The objective of this study is to demonstrate the pertinence of this hypothesis with a view to measuring the DSA sensitivity of C-Mn steels with a single test. 


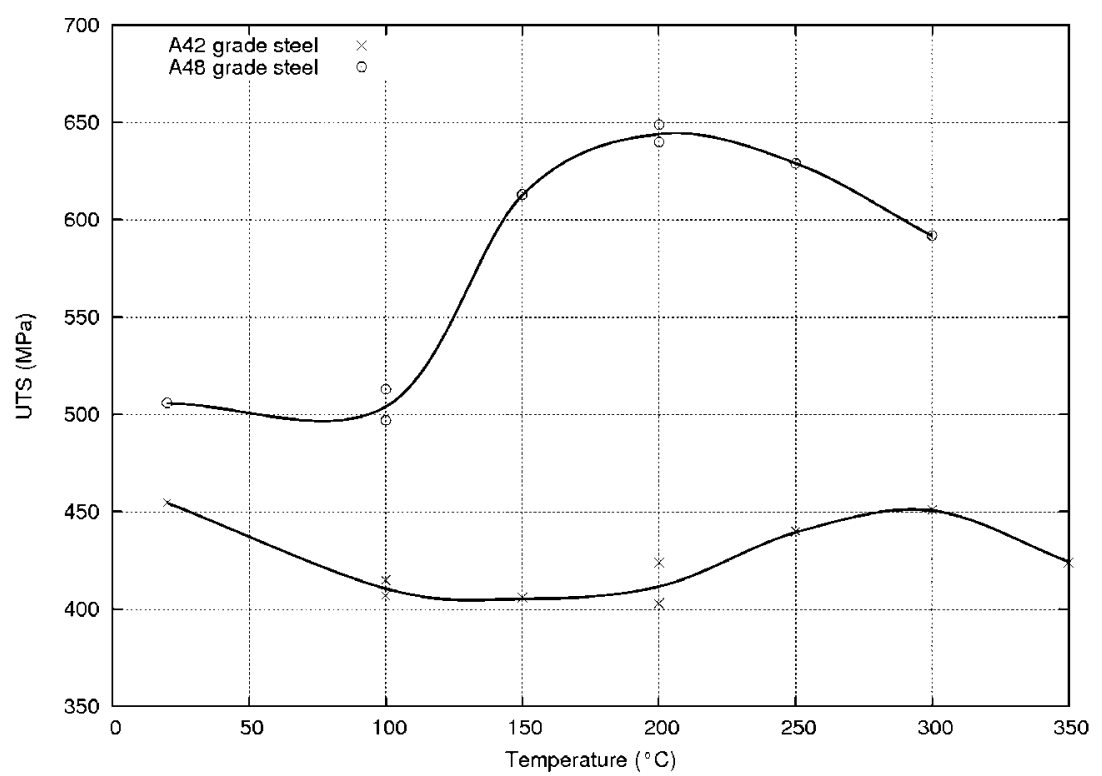

1 Ultimate tensile strength versus temperature for semikilled A48 steel and fully killed A42 steel

Thus, tensile and strain rate sensitivity tests as well as internal friction tests were performed on two C-Mn steels exhibiting large differences in their sensitivity to DSA.

\section{Materials}

The materials studied are two C-Mn steels of AFNOR (French standard) NFA 36205 grade A48 and A42, which were received as $40 \mathrm{~mm}$ thick plates. The chemical compositions are reported in Table 1. The plates were submitted to a prior normalisation thermal treatment consisting of austenitising at $870^{\circ} \mathrm{C}$ followed by air cooling, thus leading to a microstructure composed of banded ferrite and pearlite.

The A48 grade material is a silicon semikilled steel containing a very low aluminium content $(0 \cdot 004 \%)$. This amount is too small to allow full precipitation of nitrogen atoms by aluminium nitride (AlN) formation during cooling from the austenitic region. Consequently, for this heat treatment, a large amount of free nitrogen is still present in the lattice, making this alloy sensitive to DSA. The A42 grade material is a fully killed steel containing a larger aluminium content $(0.045 \%)$ so that almost all the nitrogen atoms are precipitated as aluminium nitrides, thus making this alloy relatively insensitive to DSA.

\section{Experimental techniques}

\section{Tensile tests}

Tensile tests were carried out with a strain rate of $2.4 \times 10^{-4} \mathrm{~s}^{-1}$ in the $20-300^{\circ} \mathrm{C}$ temperature range for the $\mathrm{A} 48$ steel or $20-350^{\circ} \mathrm{C}$ temperature range for the A42 steel. Cylindrical specimens (10 mm diameter) were machined in the quarter thickness longitudinal direction

Table 1 Chemical composition of A48 and A42 steels, wt-\% (balance Fe)

\begin{tabular}{|c|c|c|c|c|c|c|c|}
\hline Steel C & $N$ & $\mathrm{~s}$ & $P$ & $\mathrm{Si}$ & $M n$ & Al & 0 \\
\hline A48 & 0.0082 & ( & 0 & & & & \\
\hline
\end{tabular}

of the plates. Conventional and true stress-strain curves were plotted. The yield strength $\left(\sigma_{\mathrm{YS}}\right)$, the ultimate tensile strength $\left(\sigma_{\mathrm{UTS}}\right)$, the uniform and total elongation, the reduction of area as well as the work hardening coefficient were determined as functions of temperature.

\section{Strain rate sensitivity tests}

Strain rate sensitivity tests were performed on cylindrical specimens (4 $\mathrm{mm}$ diameter). The strain rate sensitivity coefficient

$$
S=\frac{\Delta \sigma}{\Delta \log \dot{\varepsilon}}
$$

was determined by changing the strain rate $\dot{\varepsilon}$ during tensile tests at constant temperature and for a given plastic deformation. In this study, the drop in $\dot{\varepsilon}$ (from $\dot{\varepsilon}_{1}=2.4 \times 10^{-4} \mathrm{~s}^{-1}$ to $\dot{\varepsilon}_{2}=2.4 \times 10^{-3} \mathrm{~s}^{-1}$ ) was always carried out at a plastic deformation of $4 \%$. These tests were conducted at various temperatures from 20 to 300 or $350^{\circ} \mathrm{C}$.

\section{Internal friction experiments}

Internal friction experiments were performed in the $20-300^{\circ} \mathrm{C}$ temperature range on an inverted torsion pendulum ${ }^{15}$ with an applied strain of $5 \times 10^{-6}$ and a heating rate of $130 \mathrm{~K} \mathrm{~h}^{-1}$. The samples $(3 \mathrm{~mm}$ diameter, $50 \mathrm{~mm}$ gauge length) were also machined in the quarter thickness transverse direction of the plates. This sample geometry leads to a resonant frequency of the apparatus close to $1.5 \mathrm{~Hz}$. The internal friction parameter $Q^{-1}$ was recorded as a function of test temperature.

\section{Results}

\section{Tensile tests}

On the conventional tensile curves (nominal stress versus elongation $\Delta L / L_{0}$ ), the Portevin-Le Chatelier effect (PLC) is clearly exhibited at both 100 and $200^{\circ} \mathrm{C}$ for the A48 steel, whereas for the A42 steel, no serrations resulting from the PLC effect were visible. The variations of ultimate tensile strength $\sigma_{\mathrm{UTS}}$ and total elongation are plotted against temperature on Figs. 1 


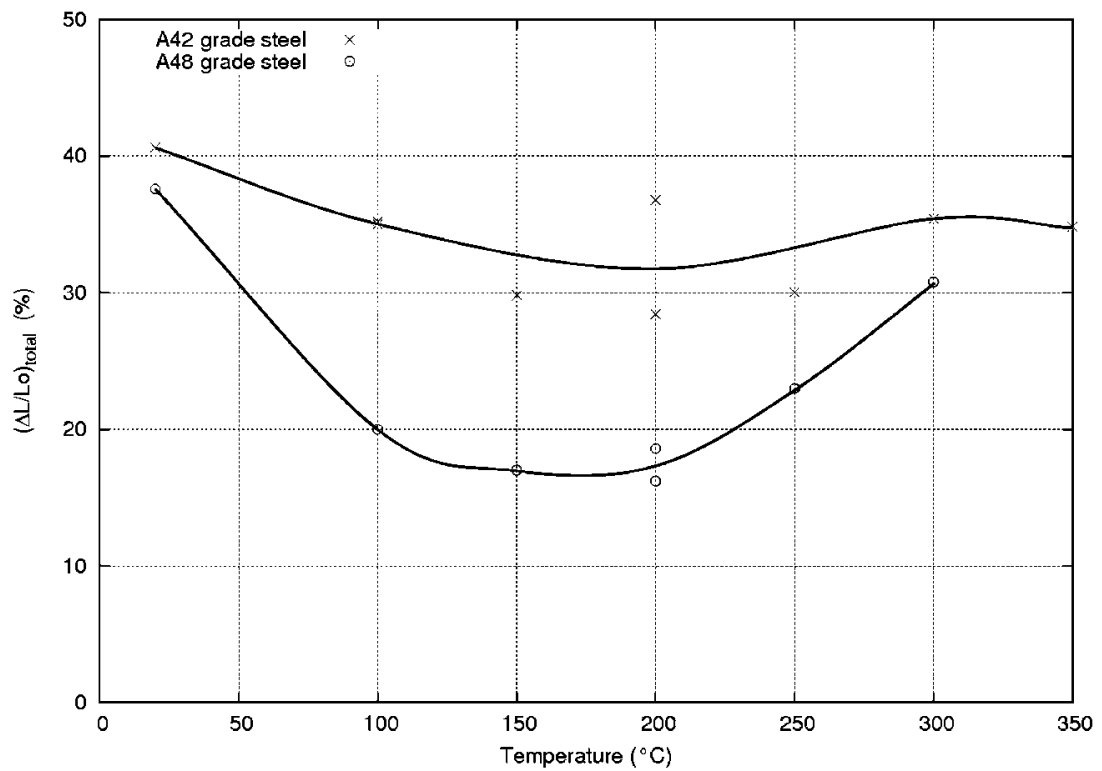

2 Total elongation versus temperature for semi-killed A48 steel and fully killed A42 steel

and 2 , respectively, for the two steels. In the temperature range tested, the two steels display ultimate tensile stress maxima associated with elongation minima, but the maximum and the minimum are more pronounced in the A48 steel than in the A42 steel. According to the larger manganese content of the A42 steel, the UTS maximum and elongation minimum are shifted to higher temperature: $250-300^{\circ} \mathrm{C}$ for the UTS of A42 compared to $200^{\circ} \mathrm{C}$ for $\mathrm{A} 48$, and $200^{\circ} \mathrm{C}$ for the elongation of $\mathrm{A} 42$ compared to $150^{\circ} \mathrm{C}$ for $\mathrm{A} 48$. The interaction existing between manganese atoms and nitrogen (or carbon) atoms ${ }^{7}$ reduces the mobility of the nitrogen and carbon atoms thus causing the appearance of dynamic strain aging to occur at higher temperatures.

\section{Strain rate sensitivity tests}

Figure 3 shows the evolution of the strain rate sensitivity coefficient $S$ versus temperature for the two steels. According to the tensile tests, for the silicon semikilled A48 steel, $S$ shows a sharp minimum in the temperature range tested, whereas, for the aluminium killed A42 steel, this minimum is less pronounced. As expected, the minimum of $S$ occurs at the same temperature as that observed for elongation $\left(200^{\circ} \mathrm{C}\right.$ for $\mathrm{A} 42$ and $150^{\circ} \mathrm{C}$ for A48).

\section{Internal friction tests}

As shown in Fig. 4, the internal friction spectrum measured on the A48 grade reveals two main peaks in the $20-300^{\circ} \mathrm{C}$ temperature range (curve 1 ). The first one, which presents a maximum at about $20^{\circ} \mathrm{C}$, can be associated with the Snoek peak (SP) resulting from carbon and nitrogen redistribution between octahedral sites in the ferritic lattice. Due to the complex interactions between nitrogen and manganese previously mentioned, the Snoek peak height is not directly proportional to $\mathrm{C}$ and $\mathrm{N}$ interstitial content in the lattice, as observed in pure iron. The second peak, observed in the 150 to $250^{\circ} \mathrm{C}$ temperature range, corresponds to the cold work peak (CWP) and is due

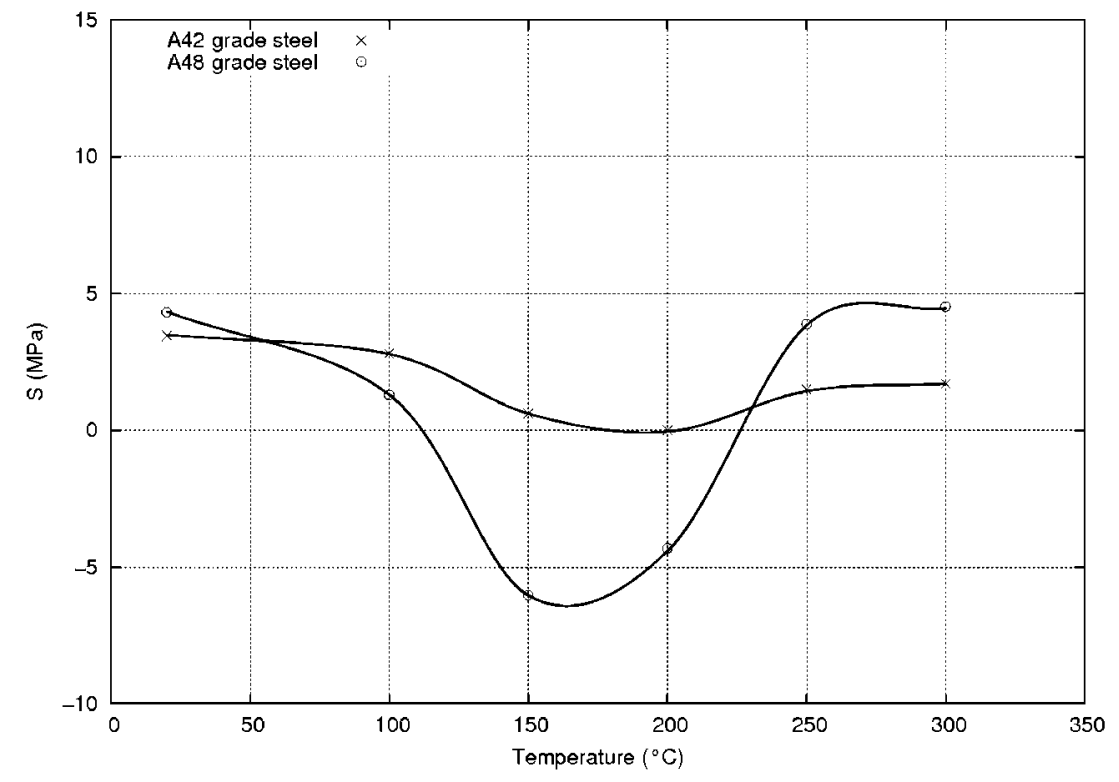

3 Strain rate sensitivity coefficient versus temperature for semikilled A48 steel and fully killed A42 steel 


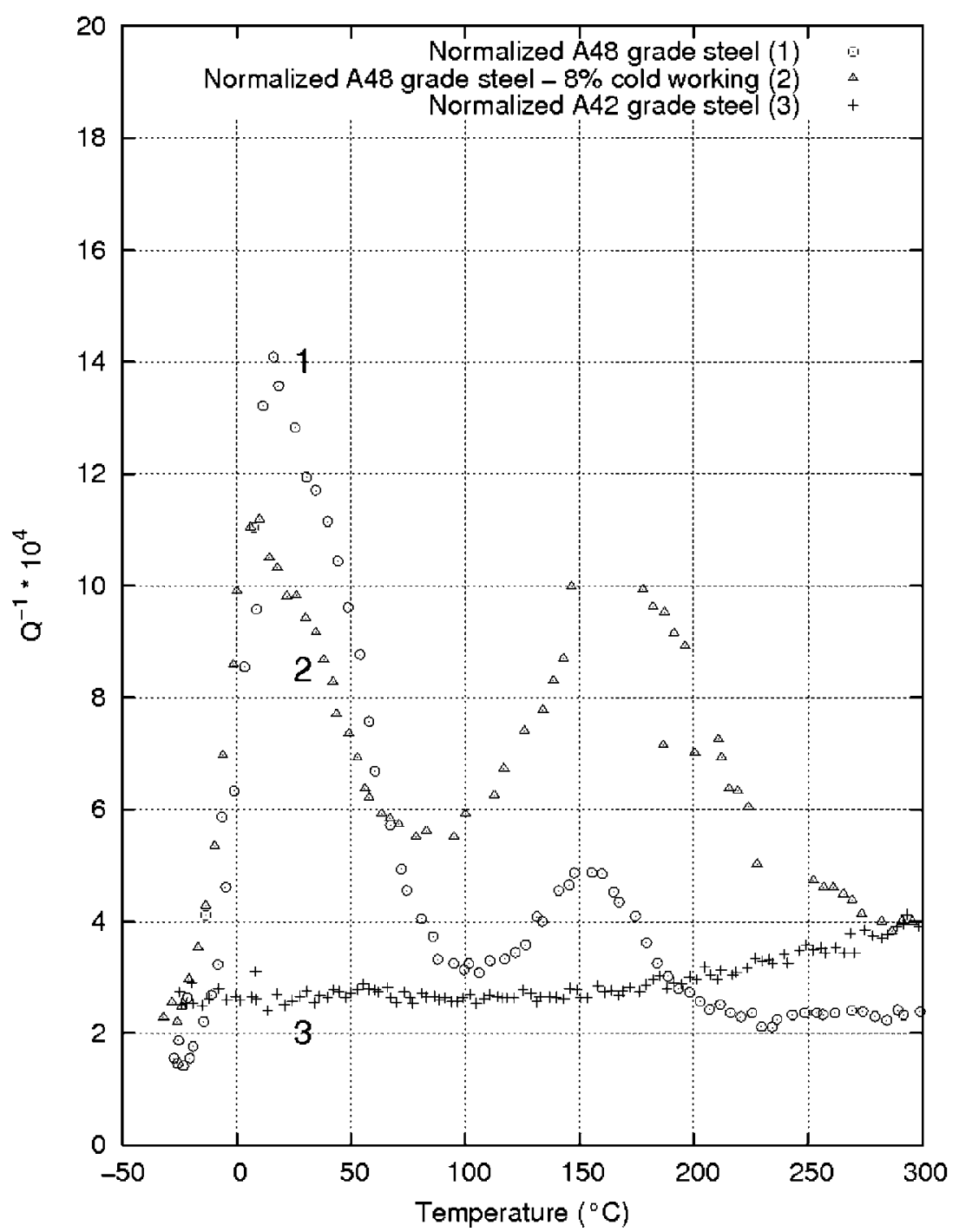

4 Internal friction $Q^{-1}$ versus temperature for A48 (normalised and cold worked conditions) and A42 steels

to the interaction between dislocations and interstitials such as carbon and nitrogen. The CWP height is related to both the density of mobile dislocations and the interstitial content in the vicinity of dislocations. This classical interpretation of the internal friction spectrum in steels is confirmed by curve 2 which represents the internal friction variation measured on this A48 grade steel after $8 \%$ cold working and one month room temperature aging. In this case, an increase of the CWP with dislocation density is observed, associated with a corresponding SP decrease, in agreement with the classical balance of interstitial atoms between lattice and dislocations. ${ }^{16}$

The internal friction spectrum measured on the A42 grade (curve 3) reveals no peak (neither SP peak nor CWP peak), in agreement with the very low nitrogen content of the ferritic lattice.

\section{Discussion}

In good agreement with their different free nitrogen content (resulting from their different aluminium content), these two carbon-manganese steels are very different regarding their sensitivity to DSA. For the A48 semikilled steel the increase in UTS is $143 \mathrm{MPa}$ and the drop in elongation $14 \%$. For the A42 fully killed steel, these values are $45 \mathrm{MPa}$ and $8 \%$, respectively.

According to these tensile tests, the strain rate sensitivity tests indicate a drop of the strain rate sensitivity coefficient $S$ of about $10 \mathrm{MPa}$ for the A48 and $3.5 \mathrm{MPa}$ for the A42 steel.

In the internal friction spectrum, the Snoek peak due to free carbon and nitrogen redistribution between equivalent octahedral sites in the lattice, which appears at $20^{\circ} \mathrm{C}$, reveals a more complex shape than in pure iron. As discussed by Koiwa, ${ }^{17}$ the SP dissymmetry in these industrial materials results from overlapping of the $\mathrm{C}$ peak (located around $39^{\circ} \mathrm{C}$ in $\alpha-\mathrm{Fe}^{18,19}$ ) and $\mathrm{N}$ peak (around $24-25^{\circ} \mathrm{C}$ in $\alpha-\mathrm{Fe}^{18-20}$ ) and essentially from the presence of substitutional manganese, which modifies the jump process of nitrogen atoms. ${ }^{7}$

The cold work peak (also known as the Snoek-Köster peak) observed between 150 and $200^{\circ} \mathrm{C}$ is due to mobility of the interstitial atoms in the dislocations stress field. The exact mechanism of this relaxation is still controversial. ${ }^{21,22}$ In the simplest model, the dislocation line pinned between two points, drags solute atoms as it bows out under the oscillating stress. At low temperature, the interstitial atom mobility is not sufficient to follow dislocations, whereas at high 


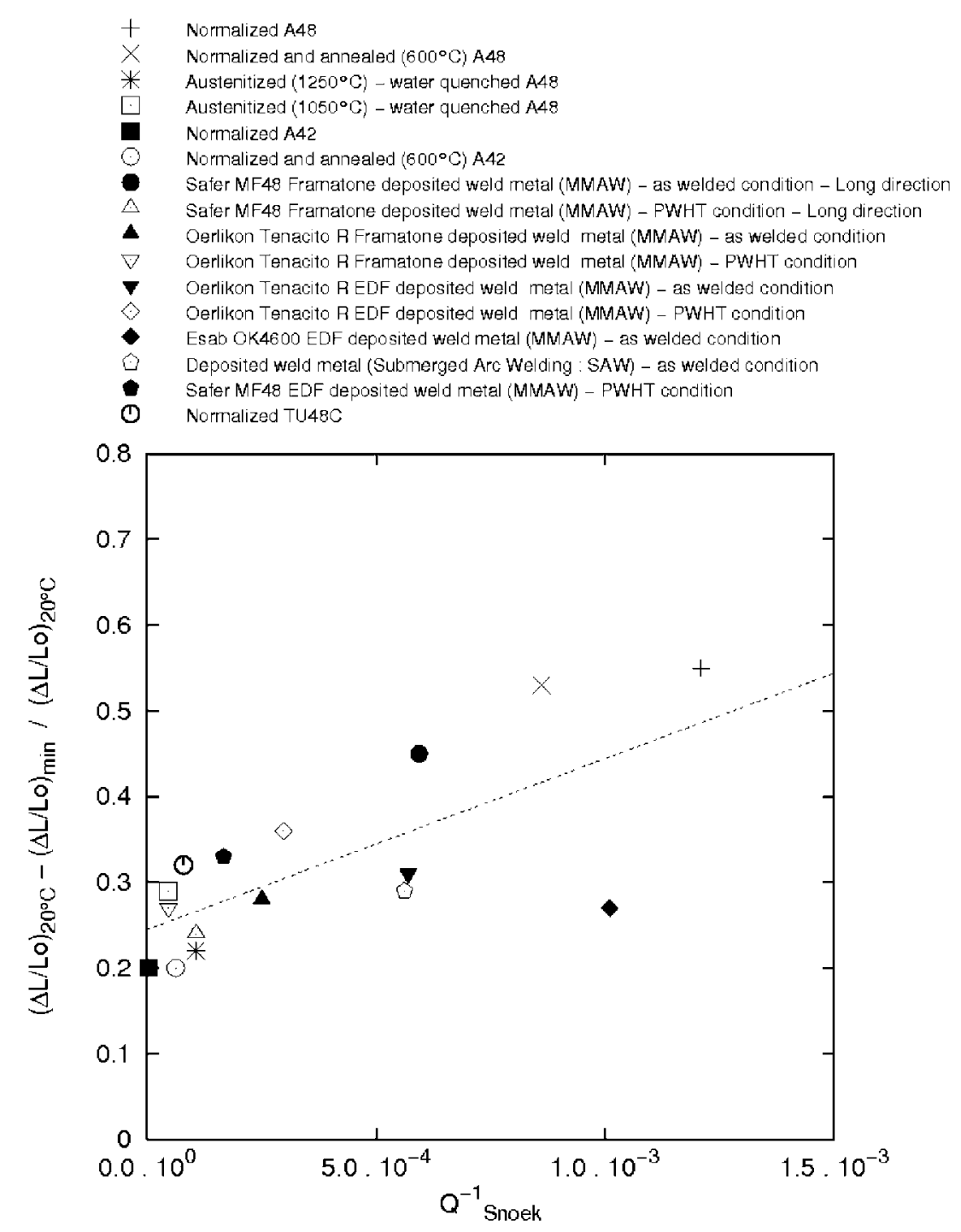

5 Ultimate tensile strength DSA sensitivity index versus Snoek peak height for various materials and treatments

temperature, this mobility is too important and, in both cases, no energy dissipation is involved. At intermediate temperatures, dragging of the interstitial atoms by the dislocations is effective and results in the energy loss measured by internal friction.

Room temperature aging and tempering of $\mathrm{Fe}-\mathrm{C}$ and $\mathrm{Fe}-\mathrm{C}-\mathrm{N}$ have been studied extensively by many authors. ${ }^{23-27}$ From these studies it appears that, after room temperature aging, the interstitial atoms are distributed through various sites:

1. Most of the nitrogen and carbon atoms are clustered in a local enriched zone which, after a sufficient time leads (in $\mathrm{Fe}-\mathrm{N}$ and $\mathrm{Fe}-\mathrm{C}$ ferrites) to $\alpha^{\prime \prime} \mathrm{Fe}_{16} \mathrm{~N}_{2}$ or $\mathrm{Fe}_{16}(\mathrm{C}, \mathrm{N})_{2}$ carbonitrides precipitation.

2. A noticeable part of the interstitial atoms are trapped in the vicinity of lattice defects such as dislocations.

3. The remaining part of the interstitial atoms are randomly distributed between the octahedral sites of the solid solution. Internal friction results by Fergusson and $\mathrm{Jack}^{23}$ showed that these atoms contribute to the Snoek peak observed in these structures. Therefore, the peak height can give a measure of the nitrogen (and carbon) content in the lattice.

For the A48 semi-killed steel, the nitrogen content near the dislocations or randomly distributed between the octahedral sites of the lattice is important in agreement with the observation of both a Snoek peak and a cold work peak. On the other hand, for the A42 fully killed steel, the internal friction spectrum is flat showing neither Snoek peak nor cold work peak, and the free nitrogen content is very low. Furthermore, the weak DSA observed for the A42 steel, in the absence of any corresponding Snoek peak or cold work peak, can be attributed partly to the insufficient resolution of our internal friction measurements, since only a few ppm of nitrogen atoms are needed to give rise to DSA. ${ }^{28}$

Nevertheless, a single internal friction test allows one to estimate the sensitivity of the steel to DSA.This method is very useful when the material is only available in small quantities as in welded metals or heat affected zones. Results (tensile and internal friction tests) on other materials $^{6}$ (base metals, deposited weld metals by manual metal arc welding (MMAW) or submerged arc welding (SAW) in as welded or post-weld heat treated (PWHT) condition) have been used to quantify this possible estimation. In pure b.c.c. metals, the Snoek peak height is proportional to $\mathrm{C}$ or $\mathrm{N}$ atoms in solid solution. Nevertheless, in steels the Snoek peak is more complex, due to overlapping of $\mathrm{C}$ and $\mathrm{N}$ peaks and also due to nitrogen Snoek peak distortion by nitrogen manganese interaction. ${ }^{7-17}$ In this case the deconvolution of the different peaks is doubtful and the 


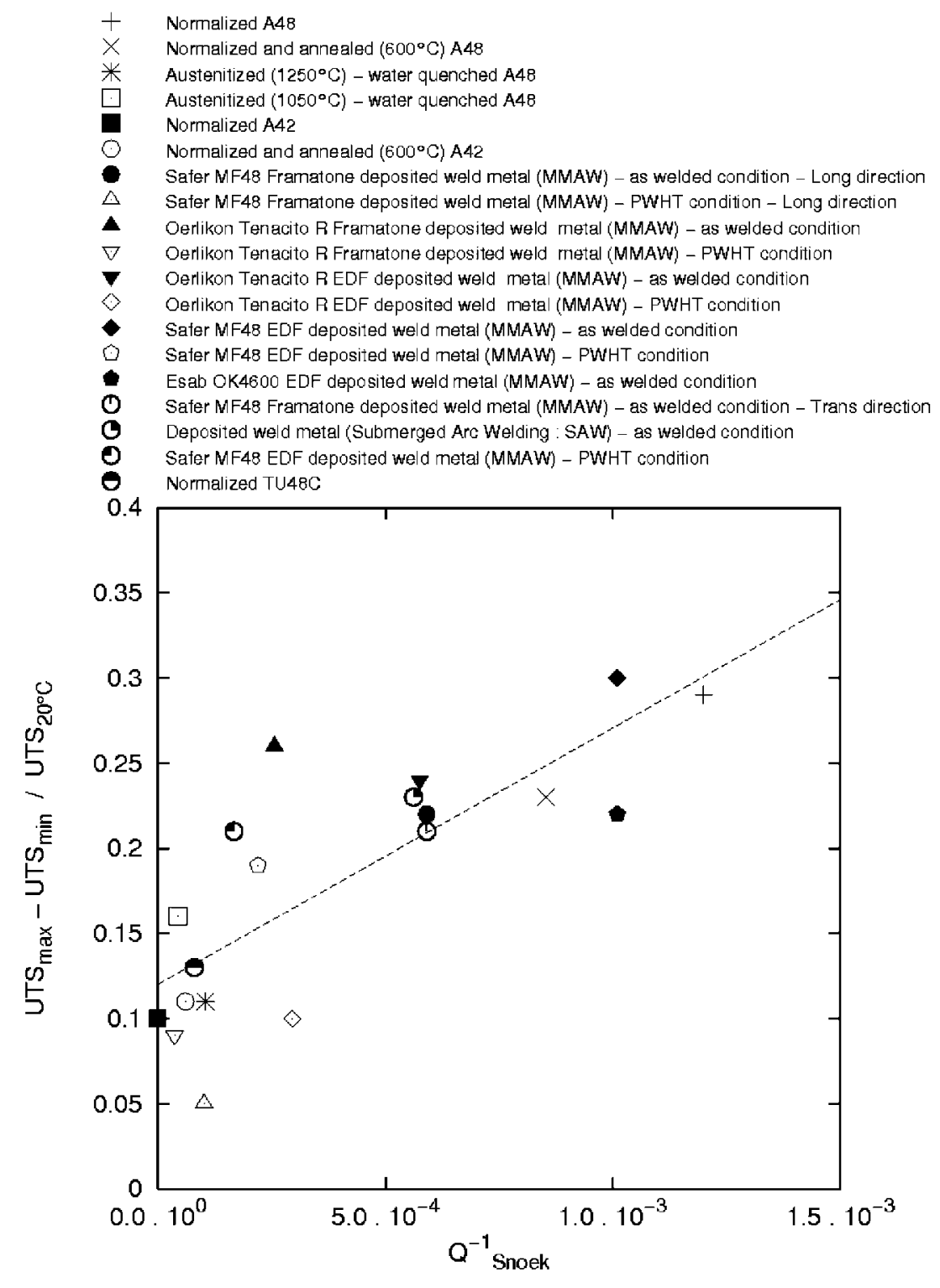

6 Elongation DSA sensitivity index versus Snoek peak height for various materials and treatments

quantitative determination of free $\mathrm{C}$ and $\mathrm{N}$ content in the lattice is not reliable. We have therefore plotted the global Snoek peak height versus two different DSA sensitivity parameters defined from an engineering point of view. The first one, $\left(\left(\Delta L / L_{0}\right)_{20}{ }^{\circ} \mathrm{C}-\left(\Delta L / L_{0}\right)_{\min }\right) /(\Delta L /$ $\left.L_{0}\right)_{20^{\circ} \mathrm{C}}$, corresponds to the loss in total elongation over the temperature range tested, relative to the total elongation measured at $20^{\circ} \mathrm{C}$. The second one, $\left((U T S)_{\max }-\right.$ $\left.(U T S)_{20{ }^{\circ} \mathrm{C}}\right) /(U T S)_{20^{\circ} \mathrm{C},}$ corresponds to the relative increase of the ultimate tensile strength. As reported in Figs. 5 and 6, a linear relationship can be plotted between the Snoek peak height and these two DSA sensitivity indexes defined above, so a single internal friction test allows estimation of the sensitivity to DSA of the steels. If the cold work peak height is plotted versus these two DSA sensitivity parameters, no correlation can be found. This result shows that it is the diffusion of interstitial solutes randomly distributed between the octahedral sites of the solid solution that is predominantly responsible for the DSA phenomenon. Contrary to a possible intuitive interpretation of DSA in steels, the interstitial atoms that are already interacting with the dislocation stress field, and responsible for the CWP, are not predominantly involved in DSA.

\section{Conclusions}

Tensile tests and strain rate sensitivity tests have been performed on two C-Mn steels: a semikilled A48 steel very sensitive to DSA and a fully killed A42 steel, relatively insensitive to DSA.

The internal friction tests have shown good correlation between the internal friction spectrum and the sensitivity to DSA. This sensitivity evaluated by the ductility loss or the UTS increase is proportionnal to Snoek peak height. This important result shows that even in industrial materials a single internal friction test can give a good evaluation of the DSA sensitivity. However, to obtain the temperature range associated with the strain rate range in which DSA occurs, tensile and strain rate sensitivity tests are needed.

\section{Acknowledgments}

The financial support of Framatome-ANP and EDF is greatly acknowledged. Thanks are due to MM. Houssin, Faure, Frund and Meyzaud for fruitful discussions and for providing the $\mathrm{C}-\mathrm{Mn}$ steels for this study. 


\section{References}

1. J. D. Baird: in 'The inhomogeneity of plastic deformation', 191; 1973, Metals Park, OH, ASM.

2. L. J. Cuddy and W. C. Leslie: Acta Metall. Mater., 1972, 20, 1157.

3. P. G. McCormick: Acta Metall., 1972, 20, 35.

4. J. L. Strudel: in 'Dislocations et déformation plastique', (ed. P. Groh et al.); 1979, Paris, Les éditions de la physique.

5. H. Neuhäuser and C. Schwink: in 'Materials science and technology' (ed. R. W. Cahn et al.), Vol. 6., 'Plastic deformation and fracture of materials', 196-243; 1993, Weinheim, London, VCH.

6. Y. Estrin and L. P. Kubin: in 'Continuum models for materials with microstructure', (ed. H. B. Mühlhaus), 395; 1995, New York, Wiley.

7. D. Wagner, J. C. Moreno and C. Prioul: Rev. Metall., 2000, 12, 1481 .

8. D. Wagner, J. C. Moreno, C. Prioul, J. M. Frund and B. Houssin Rev. Metall., 2001, 5, 1481.

9. B. J. Brindley and P. J. Worthington: Metall. Rev., 1970, 15,101.

10. P. Rodriguez: in 'Encyclopedia of materials science and engineering', (ed. R. W. Cahn), Supplementary 1, 504; 1988, Oxford, Pergamon.

11. P. G. McCormick, S. Venkadesan and C. P. Ling: Scr. Metall. Mater., 1993, 29, 1159

12. M. Lebyodkin, L. Dunin-Barkowskii, Y. Bréchet, Y. Estrin and L. P. Kubin: Acta Metall. Mater., 2000, 48, 2529.
13. W. C. Leslie: in 'Encyclopedia of materials science and engineering', 5, 4007; 1986, Oxford, Pergamon Press.

14. C. W. Marschall, M. P. Landow and G. M. Wilkowski: ASTM STP 1074, 1990, 339.

15. C. Prioul, M. Pasquet, M. Carrard, J. Plusquellec and P. Azou: Mem. Étud. Sci. Rev. Métall., 1982, 79, 203.

16. J. D. Fast: Métaux-Corros.-Ind., 1961, 435, 383

17. M. Koiwa: Philos. Mag., 1971, 24, 81.

18. A. E. Lord and D. N. Beshers: Acta Met., 1966, 14, 1659.

19. J. R. G. da Silva and R. B. McLellan: Mater. Sci. Eng., 1976, 26, 83.

20. I. G. Ritchie and R. Rawlings: Acta Met., 1967, 15, 491.

21. G. Snoek: Scr. Met., 1988, 22, 389.

22. T. S. Kê: Scr. Met., 1982, 16, 225

23. P. Fergusson and H. Jack: Proc. Heat Treatment Conf., Birmingham, UK, 1981, The Metals Society, 158.

24. R. Borrely and D. Benkirat: Acta Met., 1985, 33, 855.

25. L. Cheng, N. M. Van der Pers, A. Bottger, Th. H. De Keijser and E. J. Mittemeijer: Met. Trans A, 1990, 21A, 2857.

26. L. Cheng, N. M. Van der Pers, A. Bottger, Th. H. De Keijser and E. J. Mittemeijer: Met. Trans A, 1991, 22A, 1957.

27. L. Cheng, A. Bottger and E. J. Mittemeijer: Metall. Trans. A, 1992, 23A, 2737.

28. M. Grumbach and G. Sanz: Rev. Métall., Cah. Inf. Tech., 1970, 5, 1285 . 